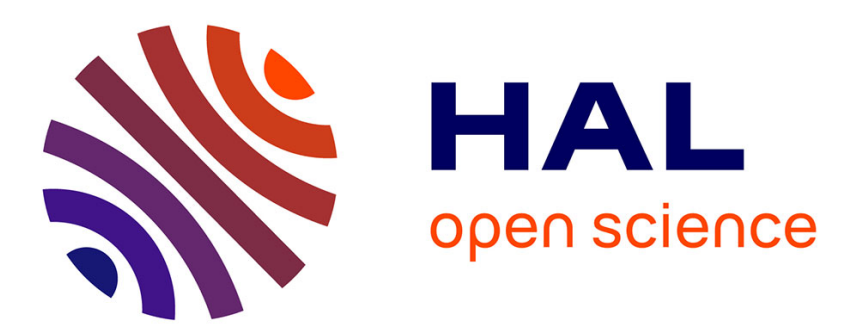

\title{
Heterogeneity of adaptive features among psychopathy variants.
}

\author{
Jonathan Bronchain, Patrick Raynal, Henri Chabrol
}

\section{To cite this version:}

Jonathan Bronchain, Patrick Raynal, Henri Chabrol. Heterogeneity of adaptive features among psychopathy variants.. Personality Disorders: Theory, Research, and Treatment, 2020, 11 (1), pp.63-68. 10.1037/per0000366 . hal-03195785

\section{HAL Id: hal-03195785 \\ https://hal.science/hal-03195785}

Submitted on 12 Apr 2021

HAL is a multi-disciplinary open access archive for the deposit and dissemination of scientific research documents, whether they are published or not. The documents may come from teaching and research institutions in France or abroad, or from public or private research centers.
L'archive ouverte pluridisciplinaire HAL, est destinée au dépôt et à la diffusion de documents scientifiques de niveau recherche, publiés ou non, émanant des établissements d'enseignement et de recherche français ou étrangers, des laboratoires publics ou privés. 
Heterogeneity of adaptive features among psychopathy variants

Jonathan Bronchain, Patrick Raynal, \& Henri Chabrol

Centre d'Etudes et de Recherches en Psychopathologie et Psychologie de la Santé, Université de Toulouse, France

\section{Author Note}

Correspondence concerning this article should be addressed to: Jonathan Bronchain, UFR de Psychologie, Université de Toulouse-Jean Jaurès, 5 allées Antonio Machado, 31058 Toulouse cedex 9. E-mail address: jonathan.bronchain@etu.univ-tlse2.fr. Tel: +33781533109. 


\begin{abstract}
Psychopathic personality traits can be conceptualized as a complex network of adaptive and maladaptive traits. Although general positive adjustment has been related to primary psychopathy and to increased emotional stability, no study focused on the distribution of specific adaptive traits through psychopathy variants. Participants were 2291 French college students who completed self-report questionnaires. A cluster analysis, based on a four-factor model of psychopathy (antagonism, narcissism, disinhibition, and emotional stability), was performed on a subsample with increased psychopathic traits $(n=378)$ and yielded three distinct groups: A Primary Psychopathy cluster (PP), a Secondary Psychopathy cluster (SP), and an Emotionally Stable-Low Antagonism cluster (ESLA). The PP cluster displayed the highest scores of leadership, logical thinking, focus, management and money smart, while the ESLA cluster had the highest scores of Composure and Extraversion. Conversely, the SP cluster exhibited reduced adaptive psychopathic traits. These results suggest that adaptive psychopathic traits are inconsistently distributed between psychopathy subtypes. Interaction effects between main factors of psychopathy are discussed.
\end{abstract}

Keywords: psychopathic traits; psychopathy subtypes; adaptive traits 
Heterogeneity of adaptive features among psychopathy variants

Psychopathy can be conceptualized as a constellation of traits including callousness, interpersonal manipulation, egocentrism, and disinhibition (Cooke \& Michie, 2001). These traits have shown consistent associations with a variety of negative outcomes such as proactive and reactive aggression, substance use behaviors, or institutionalization (Brennan, Stuppy-Sullivan, Brazil, \& Baskin-Sommers, 2017; Hecht, Berg, Lilienfeld, \& Latzman, 2016; Hemphill, Hare, \& Wong, 1998).

However, psychopathy has also demonstrated heterogeneous manifestations both at clinical and subclinical levels. Dimensionally, the various outcomes related to psychopathy have been explained by a different configuration of psychopathic traits (Lilienfeld, Watts, \& Smith, 2015). Categorically, traditional subtyping models distinguished between primary and secondary variants of psychopathy (Karpman, 1941). These two profiles have varied in their empirical support but could be defined through a consensual traits-based approach (Hicks \& Drislane, 2018). Both primary and secondary psychopathy displayed high levels of hostility and antisocial behavior. However, they differ in their motivational structure. Primary psychopathy is characterized by a profound detachment from others, with an absence of anxiety, guilt, and empathy. For this profile, antisocial behavior, deception, and manipulation could be motivated by pathological narcissism. In contrast, secondary psychopathy is associated with antagonism, impulsivity, but also guilt and heightened anxiety. Secondary psychopaths appeared to exhibit higher levels of borderline traits and covert narcissism (Skeem, Poythress, Edens, Lilienfeld, \& Cale, 2003). Consequently, antisocial behaviors in secondary psychopathy are considered to be driven by negative emotions.

An important body of literature supports the existence of primary and secondary psychopathy variants in community settings, especially in college students (Falkenbach, Stern, \& Creevy, 2014) in which psychopathic traits could be studied as extreme/maladaptive 
variants of general personality traits (e.g., Falkenbach, Reinhard, \& Zappala, 2019; Lynam \& Miller, 2018).

Comprehensive consideration of psychopathy variants is a major issue in order to (1) prevent and treat negative consequences associated with these personality characteristics, and (2) to understand atypical manifestations linked to psychopathic traits (e.g., positive adjustments). Indeed, despite the fact that psychopathic traits such as fearless dominance, boldness, or emotional stability, showed close relationships with characteristics considered adaptive, there is no consensus regarding the relevance of these components in the psychopathy construct. On the one hand, authors (Lilienfeld et al., 2012) argued that positive adjustments represent a core component of psychopathy, and reflect the "mask of sanity" reported by well-established clinical descriptions (Cleckley, 1941). Indeed, Cleckley described psychopathy as a severe personality disorder encompassing behavioral deviance (e.g., antisocial behavior, unreliability) and shallow-deceptive features (e.g., lack of remorse or shame), but also adaptive components including mask features such as superficial charm, "good intelligence", absence of nervousness, delusions and irrational thinking. On the other hand, Lynam and Miller (2012) consider positive adjustment as peripheral traits that sometimes occur in addition to psychopathic traits, but which are neither necessary nor sufficient to index this syndrome. In this line, meta-analytical evidences reported small relations between boldness-related traits and other more consensual psychopathic traits (Sleep, Weiss, Lynam, \& Miller, 2019).

Aforementioned adaptive dispositions encompass social abilities (e.g., leadership), protective features (e.g., low levels of anxiety and stress), and cognitive aptitudes (e.g., focus and strategic thinking), that could be defined as factors maximizing individual survival probability within a set environment (for a review see Durand, 2017). On the whole, adaptivity has been attributed to primary psychopathy and to the increased presence of 
boldness-related traits (e.g., Poythress \& Hall, 2011). However, to our knowledge, there is no study reporting the distribution of each of these specific traits through different profiles of psychopathy. Cluster analyses may be useful to determine subgroups of individuals sharing common psychopathic traits and to identify adaptive traits related to each profile. Thus, the objective of this study was to identify subgroups of psychopathy in a sample of college students and to explore the distribution of several adaptive traits among these profiles. We expected to find primary and secondary variants of psychopathy, and that adaptive traits were more widely distributed in primary psychopathy profiles.

\section{Method}

\section{Participants and procedures}

The data were collected through an online survey that was distributed to students from different universities in France. The link was shared on social networks in groups specifically dedicated to students. Four hundred and twelve participants were excluded for not meeting inclusion criterion (i.e., being a college student over 18 and under 28), finishing the study in a time deemed invalid (i.e., less than two seconds per item), and for invariant responding (i.e., selecting a single response option for at least $75 \%$ of items on a same questionnaire). The final sample consisted of 2291 young adults (737 males, 32\%; 1554 females, 68\%). Participants ranged in age from 18 to 28 years old $(M=19.9 \pm 1.95)$. Regarding the education domain of the participants, $31 \%$ were students in medical and paramedical courses, $13 \%$ in human sciences, $11 \%$ in science, engineering, $8 \%$ in law, $8 \%$ in economics, commerce, management and communication, $5 \%$ in letters, $5 \%$ in education and pedagogy, $4 \%$ in history, geography, political science, $1 \%$ in art and design, $1 \%$ in art history and archaeology, $0.48 \%$ in philosophy and $13 \%$ were students in another field.

In order to examine differences between psychopathy subtypes, participants were allocated to an "increased psychopathic traits" group defined by Elemental Psychopathy 
Assessment-Short Form (EPA-SF) total scores one standard deviation above the mean of the total sample ( $n=378$; males, $53 \%$; females, $47 \%)$.

\section{Measures}

Psychopathic traits were assessed using the Elemental Psychopathy Assessment-Short Form (EPA-SF; Lynam et al., 2013). It is a 72-item inventory, rated on a 5-point scale, that assesses 18 facets (with 4 items each) identified as descriptive of psychopathy (e.g., "Other people describe me as cold-hearted"). These 18 facets can be combined into a total score or used to score four factors: Interpersonal Antagonism (i.e., Callousness, Coldness, Distrustful, Manipulative, and Self-centered), Emotional Stability (i.e., Invulnerability, Self-contented, and Unconcerned), Disinhibition (i.e., Disobliged, Oppositional, Rashness, Thrill Seeking, and Urgency) and Narcissism (i.e., Anger, Arrogance, Dominance, and Self-assured).

Adaptive psychopathic traits were assessed using Durand Adaptive Psychopathic Traits Questionnaire (DAPTQ; Durand, 2017, 2018). The DAPTQ is a 41-item self-reported questionnaire, rated on a 6-point scale, which provides 9 subscales scores: Leadership (e.g., "When in a group, other people wait for me to make the decisions"), Logical Thinking (e.g., "My actions are mostly based on logical reasoning"), Composure (e.g., "I am not easily stressed out"), Creativity (e.g., "I am the most creative one out of my friends"), Fearlessness (e.g., "I do not fear potential risks when I decide to do something"), Money Smart (e.g., "I have always considered myself to be smart with money"), Focus (e.g., "I do not succumb to distraction easily"), Extraversion (e.g., "I can effortlessly mingle with any group"), and Management (e.g., "I feel organized and in control"). Higher scores represent higher adaptive resources. Of note, although Money Smart emerged from the original factor analysis, this subscale has been weakly related to boldness-related traits, and negatively linked to disinhibition component of psychopathy (Durand, 2018b). Thus, the Money Smart subscale may represent an adaptive trait not directly related to psychopathy. Nevertheless, because our 
purpose is not restricted to adaptive psychopathic traits, we chose to keep this subscale in the analysis.

\section{Statistical analysis}

A cluster analysis was performed on the "increased psychopathic traits" group to identify distinct profiles of participants based on their standardized total scores for EPA-SF factors. A hierarchical cluster analysis was then conducted (Ward's method with Euclidean distance). The dendrogram and the agglomeration schedule were used to identify the number of clusters. Then, K-means clustering was used to assign each individual to the identified clusters. Statistical analyses were performed using Statistica 12.

\section{Results}

\section{Descriptive statistics}

Means and standard deviations and Cronbach's $\alpha$ for all variables are reported in Table 1. Correlations between EPA-SF and DAPTQ dimensions are reported in the Table 2.

\section{Cluster analysis}

Based both on the dendrogram and on the aggregation curve, a four-cluster solution was identified. The agglomeration schedule showed a sudden increase in linkage distance when three clusters merged to two clusters (from 45.88 to 81.53 ). This indicated that the passage from three to two clusters would have more impact on the heterogeneity of the clusters than previous stages of the analysis. Therefore, the three-cluster solution was the most appropriate (Figure 1). A discriminant analysis showed clear differences between the three clusters (Wilks' $\lambda=0.15, \mathrm{p}<0.0001$ ) with $98.41 \%$ of original cases correctly classified.

The first group ( $n=128$, females $41 \%$ ) was called the Emotionally Stable-Low Antagonism cluster (ESLA) because it was characterized by students with the highest level of emotional stability and the lowest levels of antagonism (Table 1). The second group $(n=131$, females 58\%) included participants with high scores of antagonism, disinhibition, and 
narcissism, and the lowest levels of emotional stability and was, therefore, the Secondary Psychopathy cluster (SP). Finally, the third group $(n=119$, females $42 \%)$, named Primary Psychopathy cluster (PP), consisted of individuals demonstrating high scores of antagonism, emotional stability and narcissism, and moderately high scores of disinhibition. These three clusters represented $5.58 \%, 5.71 \%$, and $5.19 \%$ of the total sample, respectively.

Group differences between the clusters were tested using analyses of variance. Table 1 shows the results of F-tests and Tukey's post-hoc tests comparing the four clusters. These comparisons revealed that the PP cluster displayed the highest scores of leadership, logical thinking, money smart, focus, and management, while the ESLA cluster had the highest scores of composure and extraversion. SP cluster showed decreased adaptive psychopathic traits on all dimensions of the DAPTQ.

\section{Discussion}

Cluster analysis based on a four-factor model of psychopathy identified three distinct groups of participants. These clusters displayed significant differences on their levels of adaptive psychopathic traits. We can note that two of the three clusters matched with clinical descriptions of primary and secondary psychopathy. Indeed, the PP cluster displayed high levels of antagonism, emotional stability and narcissism, and moderately high levels of disinhibition, which could reflect the primary psychopathy variant. The SP cluster, characterized by high levels of antagonism, disinhibition and narcissism and low level of emotional stability, seems to capture the secondary psychopathy variant. In particular, low emotional stability and disinhibition may reflect emotion dysregulation and impulsivity which are core borderline traits (Chapman, Leung, \& Lynch, 2008). These results confirm that traditional subtyping models would be relevant to index psychopathy in community settings (Falkenbach et al., 2014). Regarding epidemiological considerations, 5.19\% and $5.71 \%$ of participants in the total sample were classified as subclinical primary and secondary 
psychopaths, respectively. Despite various methodologies, previous studies on psychopathy subtypes have found similar prevalence, with 5.5 to $12 \%$ of participants meeting criteria for psychopathy (e.g., Salekin, Trobst, \& Krioukova, 2001). The ESLA cluster, for its part, does not seem to represent a usual variant of psychopathy, given its low level of antagonism which represents a core trait of psychopathy (e.g., Verschuere et al., 2018). The ESLA cluster was probably extracted and distinguished because the EPA-SF includes an emotional stability scale which captures characteristics almost entirely adaptive, and which has been considered no sufficient to index psychopathy (see Lynam \& Miller, 2012). Similarly, the EPA-SF includes a narcissistic dimension, unlike other classical measures not isolating this factor. In sum, the ESLA cluster could encompass individuals with high emotional stability and narcissism, but not matching with classical description of psychopathy given their low level of antagonism.

Moreover, our findings underline that adaptive psychopathic traits are inconsistently distributed between clusters/subtypes, making it necessary to study them independently. The PP cluster had the highest levels of leadership, logical thinking, money smart, focus, and management. Composure and extraversion features were elevated in the PP cluster, but the ESLA cluster had the highest scores on these dimensions. Conversely, the SP cluster exhibited reduced adaptive psychopathic traits with the lowest levels on all DAPTQ dimensions. Surprisingly, DAPTQ-fearlessness did not differentiate the three groups, despite their different level of emotional stability. This result could be explained by the item content of this scale. DAPTQ-fearlessness could refer to both emotional stability and disinhibition personality traits (e.g., "I do not fear potential risks when I decide to do something"). Indeed, we reported positive correlations between DAPTQ-fearlessness and EPA-emotional stability $(r=.24, p<.01)$ and between DAPTQ-fearlessness and EPA-disinhibition $(.22, p<.01)$. Thus, unlike classical scales such as PPI-fearless dominance or TriPM-boldness, which only 
refer to emotional stability and narcissistic dimensions (Miller, Sleep, Crowe, \& Lynam, 2019), the DAPTQ-fearlessness may reflect a combination of emotional stability and disinhibition.

Comparisons between clusters suggest that a considerable number of adaptive traits is attributable to the interaction between the components of antagonism, disinhibition and emotional stability. For instance, the interaction between antagonism and emotional stability may favor leadership and management abilities in competitive environments, as observed in the PP cluster. Similarly, logical thinking and focus may be due to better monitoring of cognitive resources. The aptitude to remain calm and to inhibit uncomfortable social interactions could reduce cognitive load and favor cognitive performance in high psychopathic traits individuals. However, other adaptive psychopathic traits such as extraversion and composure could emerge from opposite relationships between antagonism and emotional stability, as observed in the ESLA cluster. The ESLA cluster is characterized by its low level of antagonism. Given that antagonism is considered as a central feature in numerous models of psychopathy, this cluster could demonstrate adaptive traits that are not specifically related to psychopathy. For instance, high composure could be related to the high level of emotional stability. Similarly, extraversion could be linked to the interaction between low antagonism and high emotional stability, which both lead to comfort in social relationships.

All these findings are in line with contemporary concerns about interactions between the main facets of psychopathy (Lilienfeld, 2018; Marcus, Fulton, \& Edens, 2013) and with a view of psychopathy as a complex network of adaptive and maladaptive traits (e.g., Bronchain, Raynal, \& Chabrol, 2019).

This study has several limitations. First, although internet data collection methods, using online completion of self-report questionnaires have shown to be consistent with more 
traditional methods (Gosling, Vazire, Srivastava, \& John, 2004), it cannot be excluded that participant self-selection may have biased the results. Second, if self-report questionnaires are consensually accepted as the best tools for assessing psychopathy in community samples (Sellbom, Lilienfeld, Fowler, \& McCrary, 2018), this argument may not hold for adaptive dispositions that should also be evaluated experimentally. Third, it is worth noting that although males represent only about a third of the original sample, they represent more than half of the "increased psychopathic traits" group. Given psychopathy variants could be influenced by gender (e.g., Colins, Fanti, Salekin, \& Andershed, 2016), the fact that gender was not taken into account to perform this cluster analysis could be arguable. Fourth, the cross-sectional design of this study does not allow to infer causality in the relationship between psychopathy and its - supposed - adaptive components. Fifth, additional measures of convergent, discriminant, or predictive validity could provide a more complete picture of adaptivity among psychopathy variants, and should be considered for future studies.

Despite these limitations, our study demonstrates some strengths, such as the recruitment of a large sample of participants with increased psychopathic traits $(N=378)$; a person-centered approach in order to better understand various profiles of psychopathic traits; and a multidimensional view of adaptive traits that encompass social, cognitive and affective features. Moreover, our results emphasize that adaptivity could take numerous forms among psychopathic individuals, and that its main component are irregularly spread throughout psychopathy subtypes. Future studies should investigate more accurately interaction between psychopathic traits to ensure a better understanding of the uncommon manifestations of this construct. 


\section{References}

Brennan, G. M., Stuppy-Sullivan, A. M., Brazil, I. A., \& Baskin-Sommers, A. R. (2017). Differentiating patterns of substance misuse by subtypes of antisocial traits in male offenders. The Journal of Forensic Psychiatry \& Psychology, 28(3), 341-356. https://doi.org/10.1080/14789949.2017.1280072

Bronchain, J., Raynal, P., \& Chabrol, H. (2019). The network structure of psychopathic personality traits in a non-institutionalized sample. Personality and Individual Differences, 146, 41-45. https://doi.org/10.1016/j.paid.2019.03.044

Chapman, A. L., Leung, D. W., \& Lynch, T. R. (2008). Impulsivity and Emotion Dysregulation in Borderline Personality Disorder. Journal of Personality Disorders, 22(2), 148-164. https://doi.org/10.1521/pedi.2008.22.2.148

Cleckley, H. (1941). The mask of sanity: An attempt to reinterpret the so-called psychopathic personality (1st edition). St Louis: Mosby.

Colins, O. F., Fanti, K. A., Salekin, R. T., \& Andershed, H. (2016). Psychopathic Personality in the General Population: Differences and Similarities Across Gender. Journal of Personality Disorders, 31(1), 49-74. https://doi.org/10.1521/pedi_2016_30_237

Cooke, D., \& Michie, C. (2001). Refining the construct of psychopathy: Towards a hierarchical model. Psychological Assessment, 13(2), 171-188. https://doi.org/10.1037//1040-3590.13.2.171

Durand, G. (2017). The Durand Adaptive Psychopathic Traits Questionnaire: Development and Validation. Journal of Personality Assessment, 101(2), 140-149. https://doi.org/10.1080/00223891.2017.1372443

Durand, G. (2018a). A French translation and validation of the Durand Adaptive Psychopathic Traits Questionnaire: An investigation with community samples from France and 
Canada. PloS One, 13(9), e0204214-e0204214.

https://doi.org/10.1371/journal.pone.0204214

Durand, G. (2018b). Incremental Validity of the Durand Adaptive Psychopathic Traits Questionnaire Above Self-Report Psychopathy Measures in Community Samples. Journal of Personality Assessment, 1-10. https://doi.org/10.1080/00223891.2018.1464456

Falkenbach, D. M., Reinhard, E. E., \& Zappala, M. (2019). Identifying Psychopathy Subtypes Using a Broader Model of Personality: An Investigation of the Five Factor Model Using Model-Based Cluster Analysis. Journal of Interpersonal Violence, 0886260519831388. https://doi.org/10.1177/0886260519831388

Falkenbach, D. M., Stern, S. B., \& Creevy, C. (2014). Psychopathy variants: Empirical evidence supporting a subtyping model in a community sample. Personality Disorders, 5(1), 10-19.

Gosling, S. D., Vazire, S., Srivastava, S., \& John, O. P. (2004). Should We Trust Web-Based Studies? A Comparative Analysis of Six Preconceptions About Internet Questionnaires. American Psychologist, 59(2), 93-104. http://dx.doi.org/10.1037/0003-066X.59.2.93

Hecht, L. K., Berg, J. M., Lilienfeld, S. O., \& Latzman, R. D. (2016). Parsing the heterogeneity of psychopathy and aggression: Differential associations across dimensions and gender. Personality Disorders, 7(1), 2-14. https://doi.org/10.1037/per0000128

Hemphill, J. F., Hare, R. D., \& Wong, S. (1998). Psychopathy and recidivism: A review. Legal and Criminological Psychology, 3(1), 139-170. https://doi.org/10.1111/j.20448333.1998.tb00355.x 
Hicks, B. M., \& Drislane, L. F. (2018). Variants (“Subtypes”) of Psychopathy. In Patrick, C. J. (Ed.). Handbook of Psychopathy. Guilford Publications.

Karpman, B. (1941). On the need of separating psychopathy into two distinct clinical types: The symptomatic and the idiopathic. Journal of Criminal Psychopathology, (3), 112137.

Lilienfeld, S. O. (2018). The Multidimensional Nature of Psychopathy: Five Recommendations for Research. Journal of Psychopathology and Behavioral Assessment, 40(1), 79-85. https://doi.org/10.1007/s10862-018-9657-7

Lilienfeld, S. O., Patrick, C. J., Benning, S. D., Berg, J., Sellbom, M., \& Edens, J. F. (2012). The role of fearless dominance in psychopathy: Confusions, controversies, and clarifications. Personality Disorders, 3(3), 327-340. https://doi.org/10.1037/a0026987

Lilienfeld, S. O., Watts, A. L., \& Smith, S. F. (2015). Successful Psychopathy: A Scientific Status Report. Current Directions in Psychological Science, 24(4), 298-303. https://doi.org/10.1177/0963721415580297

Lynam, D. R., \& Miller, J. D. (2012). Fearless dominance and psychopathy: A response to Lilienfeld et al. Personality Disorders, 3(3), 341-353. https://doi.org/10.1037/a0028296

Lynam, D. R., \& Miller, J. D. (2018). Psychopathy and personality: An articulation of the benefits of a trait-based approach. In Handbook of Psychopathy (2nd ed., pp. 259280). New York: Guilford.

Lynam, D. R., Sherman, E. D., Samuel, D., Miller, J. D., Few, L. R., \& Widiger, T. A. (2013). Development of a Short Form of the Elemental Psychopathy Assessment. Assessment, 20(6), 659-669. https://doi.org/10.1177/1073191113502072 
Marcus, D. K., Fulton, J. J., \& Edens, J. F. (2013). The two-factor model of psychopathic personality: Evidence from the psychopathic personality inventory. Personality Disorders, 4(1), 67-76. https://doi.org/10.1037/a0025282

Miller, J. D., Sleep, C. E., Crowe, M. L., \& Lynam, D. R. (2019). Psychopathic boldness: Narcissism, self-esteem, or something in between? https://doi.org/10.31234/osf.io/5mfyr

Poythress, N. G., \& Hall, J. R. (2011). Psychopathy and impulsivity reconsidered. Aggression and Violent Behavior, 16(2), 120-134. https://doi.org/10.1016/j.avb.2011.02.003

Resseguier, N., Giorgi, R., \& Paoletti, X. (2011). Sensitivity Analysis When Data Are Missing Not-at-random. Epidemiology, 22(2). Retrieved from https://journals.lww.com/epidem/Fulltext/2011/03000/Sensitivity_Analysis_When_Da ta_Are_Missing.25.aspx

Salekin, R. T., Trobst, K. K., \& Krioukova, M. (2001). Construct Validity of Psychopathy in a Community Sample: A Nomological Net Approach. Journal of Personality Disorders, 15(5), 425-441. https://doi.org/10.1521/pedi.15.5.425.19196

Skeem, J. L., Poythress, N., Edens, J. F., Lilienfeld, S. O., \& Cale, E. M. (2003).

Psychopathic personality or personalities? Exploring potential variants of psychopathy and their implications for risk assessment. Aggression and Violent Behavior, 8(5), 513-546. https://doi.org/10.1016/S1359-1789(02)00098-8

Sleep, C. E., Weiss, B., Lynam, D. R., \& Miller, J. D. (2019). An examination of the Triarchic Model of psychopathy's nomological network: A meta-analytic review. Clinical Psychology Review, 71, 1-26. https://doi.org/10.1016/j.cpr.2019.04.005

Verschuere, B., van Ghesel Grothe, S., Waldorp, L., Watts, A. L., Lilienfeld, S. O., Edens, J. F., ... Noordhof, A. (2018). What features of psychopathy might be central? A network analysis of the Psychopathy Checklist-Revised (PCL-R) in three large 
samples. Journal of Abnormal Psychology, 127(1), 51-65.

https://doi.org/10.1037/abn0000315 
Table 1. Cluster analysis based on the four EPA-SF factors. Cluster comparison using ANOVA and post-hoc tests.

\begin{tabular}{|c|c|c|c|c|c|c|c|c|c|c|}
\hline & \multirow{2}{*}{$\begin{array}{l}\text { Sample } \\
\begin{array}{c}N=2291 \\
M(S D)\end{array}\end{array}$} & \multirow[t]{2}{*}{$\alpha$} & \multirow[t]{2}{*}{ Range } & \multirow[b]{2}{*}{$\begin{array}{c}\text { LPT } \\
n=1913\end{array}$} & \multirow[b]{2}{*}{$\begin{array}{c}\text { IPT } \\
n=378\end{array}$} & \multicolumn{3}{|c|}{$\begin{array}{l}\text { Cluster } \\
M(S D)\end{array}$} & \multirow[b]{2}{*}{$F$} & \multirow[b]{2}{*}{$\begin{array}{l}\text { Significant } \\
\text { comparisons }\end{array}$} \\
\hline & & & & & & $\begin{array}{c}\text { ESLA } \\
n=128\end{array}$ & $\begin{array}{c}\text { SP } \\
n=131\end{array}$ & $\begin{array}{c}\text { PP } \\
n=119\end{array}$ & & \\
\hline Antagonism & $45.44(10.59)$ & .85 & $20-94$ & $42,98(8.57)$ & $57.88(11.10)$ & $48.32(6.25)$ & $57.49(8.31)$ & $68.58(7.79)$ & $225.04 *$ & $\mathrm{PP}>\mathrm{SP}>\mathrm{ESLA}$ \\
\hline Emotional stability & $33.42(9.69)$ & .87 & $12-60$ & $31,96(9.08)$ & $40.79(9.32)$ & $47.35(5.42)$ & $30.96(5.72)$ & $44.55(6.49)$ & $286,42 *$ & ESLA $>\mathrm{PP}>\mathrm{SP}$ \\
\hline Disinhibition & $58.44(11.61)$ & .81 & $28-109$ & $56,13(10.36)$ & $70.15(10.53)$ & $68.20(8.27)$ & $77.60(8.13)$ & $64.05(10.22)$ & $77.13^{*}$ & $\mathrm{SP}>\mathrm{ESLA}>\mathrm{PP}$ \\
\hline Narcissism & $43.33(8.54)$ & .75 & $21-74$ & $41,54(7.55)$ & $52.39(7.43)$ & $52.28(6.99)$ & $52.70(7.52)$ & $52.16(7.83)$ & 0.18 & n.a. \\
\hline Leadership & $13.86(3.51)$ & .75 & $4-24$ & $13,43(3.39)$ & $16.01(3.27)$ & $16.21(2.71)$ & $15.32(3.66)$ & $16.54(3.27)$ & $4.84^{*}$ & $\mathrm{PP}>\mathrm{SP}$ \\
\hline Logical thinking & $19.92(4.43)$ & .78 & $6-30$ & $20,02(4.25)$ & $19.44(5.21)$ & $19.50(4.44)$ & $16.44(4.47)$ & $22.68(4.78)$ & $58.30^{*}$ & $\mathrm{PP}>\mathrm{ESLA}>\mathrm{SP}$ \\
\hline Composure & $17.37(7.12)$ & .88 & $5-36$ & $16,41(6.72)$ & $22.20(7.13)$ & $26.67(5.14)$ & $16.32(5.73)$ & $23.88(5.93)$ & $118.10^{*}$ & $\mathrm{ESLA}>\mathrm{PP}>\mathrm{SP}$ \\
\hline Creativity & $14.71(4.64)$ & .84 & $4-24$ & $14,64(4.63)$ & $15.05(4.70)$ & $15.42(4.70)$ & $14.66(4.72)$ & $15.10(4.67)$ & 0.84 & n.a. \\
\hline Fearlessness & $20.30(5.90)$ & .81 & $6-36$ & $19,34(5.52)$ & $25.15(5.36)$ & $25.96(5.23)$ & $24.61(5.06)$ & $24.86(5.74)$ & 2.33 & n.a. \\
\hline Money smart & $12.03(3.07)$ & .63 & $3-18$ & $12,25(2.97)$ & $10.88(3.32)$ & $10.64(3.37)$ & $10.03(2.92)$ & $12.06(3.36)$ & $12.88^{*}$ & $\mathrm{PP}>\mathrm{ESLA}>\mathrm{SP}$ \\
\hline Focus & $11.31(3.98)$ & .84 & $4-23$ & $11,43(3.97)$ & $10.74(4.01)$ & $10.82(3.93)$ & $9.42(3.59)$ & $12.10(4.10)$ & $14.85^{*}$ & $\mathrm{PP}>\mathrm{ESLA}>\mathrm{SP}$ \\
\hline Extroversion & $19.14(6.17)$ & .80 & $6-36$ & $18,46(5.89)$ & $22.64(6.35)$ & $25.60(5.26)$ & $20.97(6.54)$ & $21.27(6.13)$ & $23.73^{*}$ & ESLA > PP, SP \\
\hline Management & $10.92(3.33)$ & .71 & $2-18$ & $10,94(3.32)$ & $10.80(3.34)$ & $11.29(2.75)$ & $9.17(3.34)$ & $12.08(3.23)$ & $29.48^{*}$ & $\mathrm{PP}>\mathrm{ESLA}, \mathrm{SP}$ \\
\hline
\end{tabular}

Note. LPG: Low Psychopathic Traits group; IPT: Increased Psychopathic Traits group; ESLA: Emotionally Stable-Low Antagonism cluster; SP: Secondary Psychopathy cluster; PP: Primary Psychopathy cluster.

$* p<.01$. 
Table 2. Intercorrelations between EPA-SF and DAPTQ dimensions.

\begin{tabular}{|c|c|c|c|c|c|c|c|c|c|c|c|c|c|}
\hline Variable & 1 & 2 & 3 & 4 & 5 & 6 & 7 & 8 & 9 & 10 & 11 & 12 & 13 \\
\hline 1. Antagonism & - & $.15^{*}$ & $.33^{*}$ & $.25^{*}$ & $.10 *$ & $.11^{*}$ & $.13^{*}$ & $-.05^{*}$ & $.21 *$ & $-.07 *$ & -.02 & $-.08^{*}$ & $-.06^{*}$ \\
\hline 2. Emotional stability & -.07 & - & $-.09 *$ & $.18^{*}$ & $.27 *$ & $.37 *$ & $.84 *$ & $.06^{*}$ & $.38 *$ & $.10^{*}$ & $.18^{*}$ & $.31^{*}$ & $.32 *$ \\
\hline 3. Disinhibition & $-.13 *$ & $-.41 *$ & - & $.31^{*}$ & -.01 & $-.49 *$ & -.01 & .01 & $.40 *$ & $-.37 *$ & $-.34 *$ & $.08^{*}$ & $-.42 *$ \\
\hline 4. Narcissism & -.09 & -.05 & .02 & _ & $.63^{*}$ & $-.09 *$ & $.16^{*}$ & $.08^{*}$ & $.31 *$ & $-.19 *$ & .02 & $.60 *$ & $.12 *$ \\
\hline 5. Leadership & -.02 & $.16^{*}$ & $-.16^{*}$ & $.59 *$ & - & $.12 *$ & $.22 *$ & $.09^{*}$ & $.25^{*}$ & -.04 & $.18^{*}$ & $.48 *$ & $.28 *$ \\
\hline 6. Logical thinking & $.30 *$ & $.39 *$ & $-.63 *$ & $-.14 *$ & .08 & - & $.28 *$ & -.03 & -.01 & $.33^{*}$ & $.27 *$ & -.01 & $.34 *$ \\
\hline 7. Composure & -.11 & $.81^{*}$ & $-.28 *$ & -.09 & .05 & $.26^{*}$ & - & .03 & $.36 *$ & $.06^{*}$ & $.14^{*}$ & $.29 *$ & $.28 *$ \\
\hline 8. Creativity & -.01 & .06 & -.01 & -.02 & .08 & -.01 & .01 & - & $.08 *$ & -.01 & .03 & $.15^{*}$ & $.05 *$ \\
\hline 9. Fearlessness & -.06 & $.24 *$ & $.22^{*}$ & .12 & $.24 *$ & -.09 & $.23^{*}$ & .08 & - & $-.09 *$ & .04 & $.26^{*}$ & .04 \\
\hline 1. Money Smart & $.14 *$ & $.13^{*}$ & $-.38 *$ & $-.18 *$ & -.07 & $.36^{*}$ & .09 & .00 & -.12 & - & $.25^{*}$ & $-.11^{*}$ & $.27 *$ \\
\hline 11. Focus & .09 & $.16^{*}$ & $-.38^{*}$ & .07 & $.16^{*}$ & $.26^{*}$ & $.14^{*}$ & .09 & .07 & $.25^{*}$ & - & .03 & $.46^{*}$ \\
\hline 12. Extroversion & $-.37 *$ & $.23^{*}$ & -.01 & $.52 *$ & $.39 *$ & -.08 & $.16^{*}$ & $.14^{*}$ & $.19 *$ & $-.16^{*}$ & -.01 & - & $.18 *$ \\
\hline 13. Management & .04 & $.33^{*}$ & $-.51 *$ & .11 & $.26^{*}$ & $.30 *$ & $.26^{*}$ & $.14^{*}$ & .01 & $.28^{*}$ & $.43^{*}$ & $.14^{*}$ & - \\
\hline
\end{tabular}

Note. Intercor relations in the moderately high psychopathy group $(n=378)$ are presented below the diagonal, and intercorrelations in the total sample $(N=$ 2291) are presented above the diagonal.

$* p<.01$. 
$\cdots$ ESLA - SP - - PP

2.5

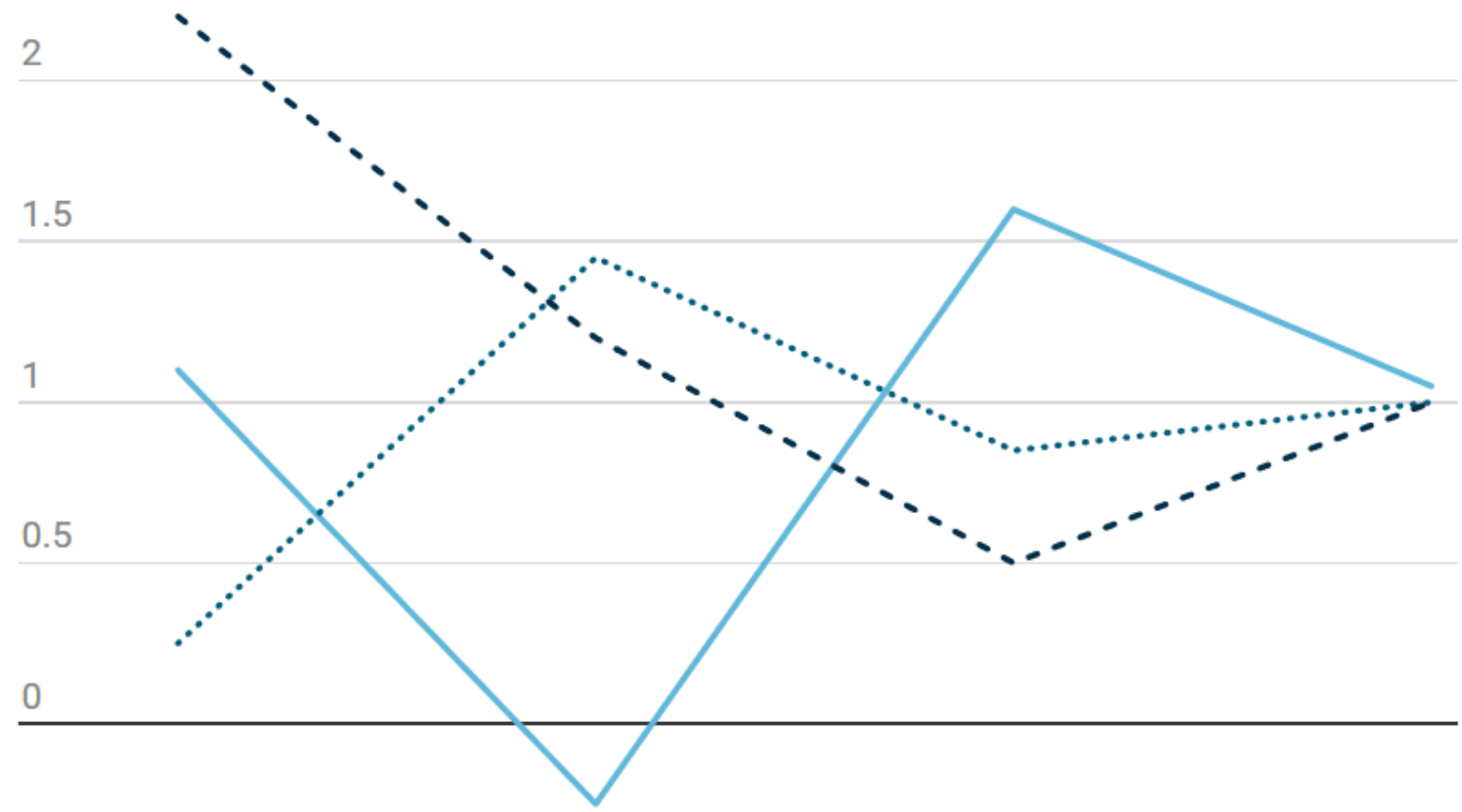

$-0.5$

$-1$

Fig. 1. Three-cluster solution based on z-scores for the EPA-SF factors indicated on the $x$ axis. ESLA: Emotionally Stable-Low Antagonism cluster; SP: Secondary Psychopathy cluster; PP: Primary Psychopathy cluster. 